\title{
A novel technique for fabrication of near-net-shape CMCs
}

\author{
A DEY, M CHATTERJEE*, M K NASKAR, S DALUI ${ }^{\dagger}$ and K BASU ${ }^{*}$ \\ Sol-Gel Division, ${ }^{\dagger}$ Composite Division, Central Glass and Ceramic Research Institute, Kolkata 700 032, India \\ ${ }^{\ddagger}$ Regional Research Laboratory, Bhopal 462 026, India
}

\begin{abstract}
A sol-gel vacuum infiltration technique has been developed for the fabrication of near-net-shape ceramic matrix composites (CMCs) using discontinuous mullite fibre preform with 15 vol.\% of fibre content and $\mathrm{ZrO}_{2} \cdot 10 \mathrm{wt} \% \mathrm{Y}_{2} \mathrm{O}_{3}$ sol as the infiltrant. Effect of sol viscosity, number of infiltration and calcination temperature on physico-mechanical properties of fabricated CMCs were examined. Characterization of the fibre preform, matrix material (in the form of ceramic specimen without fibre) and the developed CMCs were performed by X-ray diffraction (XRD) and scanning electron microscopy (SEM). XRD indicated the presence of cubic $(c)$ and tetragonal $(t)$ zirconia in both the CMCs and the ceramic specimens calcined even at $1400^{\circ} \mathrm{C}$. Flexural strength of the CMCs and the ceramic specimens (calcined at $1400^{\circ} \mathrm{C}$ ), determined by the three-point bending test, was found to be about $14 \mathrm{mPa}$ and $1.40 \mathrm{mPa}$, respectively. SEM indicated multiple fracture of the matrix which gave rise to pseudo elasticity. This is also evident from the load-displacement curve of the three-point bend test. SEM studies also indicated fibre pull-out in the fracture surface of the CMCs.
\end{abstract}

Keywords. Sol-gel; vacuum infiltration; fibre reinforced ceramic matrix composites.

\section{Introduction}

Ceramic fibre reinforced ceramic matrix composites (CMCs) have attracted attention now-a-days and may be considered as promising alternative to monolithic ceramics (brittle) for obtaining structural materials suitable for engineering applications (Gu et al 2000). As the solgel method of producing CMCs has specific advantages (Russel-Floyd et al 1993), an attempt has been made, in the present investigation, for the development of a technique for the fabrication of near-net-shape CMCs using discontinuous mullite fibre preforms and zirconia-yttria $\left(\mathrm{ZrO}_{2} \cdot 10\right.$ wt. $\left.\% \mathrm{Y}_{2} \mathrm{O}_{3}\right)$ sol (Chakrabarty et al 2001).

\section{Experimental}

The as-received discontinuous mullite fibre preforms with 15 vol. $\%$ fibre content and dimensions of $\sim 100 \mathrm{~mm}$ (diameter) $\times 10 \mathrm{~mm}$ (thick) [manufactured by the Orient Cerwool Limited, Lakhtar (Gujarat)] were cut into small pieces of approximate dimensions $40 \times 7 \times 6 \mathrm{~mm}$ and activated at $500^{\circ} \mathrm{C}$ for $1 \mathrm{~h}$ in air. The parent zirconium acetate sol of composition $\mathrm{ZrO}_{2} \cdot 10 \mathrm{wt} \% \mathrm{Y}_{2} \mathrm{O}_{3}$ and viscosity $2.8 \pm 1 \mathrm{mPas}$ was prepared by the precipitationpeptization technique (Chakrabarty et al 2001). From this sol, other sols of viscosities $40-60 \mathrm{mPa}$ s were prepared by evaporation and were used as infiltrants. The vacuum infiltration technique (Russel-Floyd et al 1993) was

*Author for correspondence followed for the fabrication of CMCs. Table 1 summarizes the experimental conditions used for the fabrication of CMCs. Further, rectangular bars (ceramic specimen without fibre) of approximate dimensions $41 \times 9 \times 8 \mathrm{~mm}$ were fabricated under an isostatic pressure of 1.5 ton using oxide powder of -300 mesh (calcined at $1000^{\circ} \mathrm{C}$ ), obtained from the $\mathrm{ZrO}_{2} \cdot 10$ wt. $\% \mathrm{Y}_{2} \mathrm{O}_{3}$ sol as prepared above, and calcined at $1400^{\circ} \mathrm{C}$ for $1 \mathrm{~h}$. The fabricated materials were characterized by XRD (Model: Philips PW 1730), SEM (Model: Leo 400c) and three-point bending strength measurement using Instron Universal Testing machine (Model: $5500 \mathrm{R}$ ). Each strength datum is an average over 6 samples.

\section{Results and discussion}

Table 1 presents the characteristics of the CMCs obtained in the present investigation. In the present process, multiple infiltration cycles followed by intermediate heattreatment at $800^{\circ} \mathrm{C}$ was adopted to minimize matrix cracking caused due to large shrinkage during drying of the infiltrated materials. The final calcination temperature of $1400^{\circ} \mathrm{C}$ for $1 \mathrm{~h}$, in the range $1000-1400^{\circ} \mathrm{C}$, was found to be the optimum. Comparing the results of run nos. 1, 2 and 3 of table 1, it is clear that with the increase in the no. of infiltrations, keeping other parameters unaltered, although the overall strength of the infiltrated material increases (run nos. 2 and 3), they fail to exhibit the reinforcement characteristics (figure 1a). This may be due to the development of strong interaction between the fibre and the excess matrix material for excess loading. On the other hand, the pseudo-elastic behaviour of the 
product of run no. 1 is evident from figure $1 \mathrm{~b}$. Figures 2 and 3 represent the SEM of the as-received (uninfiltrated) fibre preform and the fracture surface of the product of run no. 1 of table 1 , respectively. Figure 3 clearly indicates fibre pull-out in the CMC. The reinforced fibres acted as crack arresters which prevented the propagation of cracks.

XRD of the CMCs fabricated at $1400^{\circ} \mathrm{C}$ confirmed the presence of both $c$ - and $t-\mathrm{ZrO}_{2}$ along with the mullite phase, without any formation of monoclinic $\mathrm{ZrO}_{2}$ poly- morphs. Obviously, the $\mathrm{Y}_{2} \mathrm{O}_{3}$ additive in the matrix materials helped to retain $t-\mathrm{ZrO}_{2}$ at $1400^{\circ} \mathrm{C}$ by inhibiting grain growth (Chakrabarty et al 2001). Under identical conditions of heat-treatment, the ceramic specimens, without any fibre-reinforcing materials, exhibited a flexural strength of about $1.40 \mathrm{mPa}$ (Load at break: $24 \cdot 12 \mathrm{~N}$ ). This low value of the flexural strength (figure 1c) supports the necessity of mullite fibre reinforcing materials in the specimens, inspite of the retainment of $c-/ t-\mathrm{ZrO}_{2}$ in the matrix (identified by XRD).

Table 1. Characteristics of CMCs obtained under different experimental conditions.

\begin{tabular}{lcccrl}
\hline Run no. & $\begin{array}{c}\text { Sol viscosity } \\
(\mathrm{mPa} \mathrm{s})\end{array}$ & $\begin{array}{c}\text { Final calcination } \\
\text { temperature }\left({ }^{\circ} \mathrm{C}\right)\end{array}$ & $\begin{array}{c}\text { Load at break } \\
(\mathrm{N})\end{array}$ & $\begin{array}{c}\text { Flexural strength } \\
(\mathrm{mPa})\end{array}$ & Remarks \\
\hline 1. & $60 \pm 1(1)^{\dagger}, 40 \pm 1(2)^{\dagger}$ & 1400 & 28.96 & 5.21 & Good surface (CMC character) \\
2. & $60 \pm 1(5)^{\dagger}$ & 1400 & 265.91 & 11.49 & Good surface (ceramic character) \\
3. & $60 \pm 1(1)^{\dagger}, 40 \pm 1(4)^{\dagger}$ & 1400 & 301.76 & 13.95 & Good surface (ceramic character) \\
\hline
\end{tabular}

${ }^{\dagger}$ Number in the parenthesis indicates the no. of infiltration.
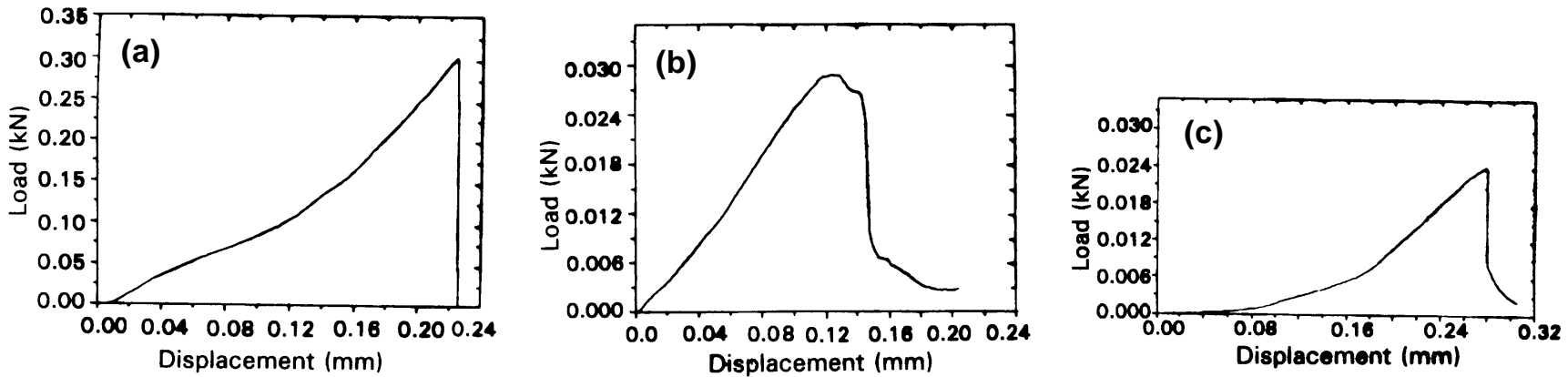

Figure 1. Load displacement curves of (a) the product of run no. 3 of table 1, (b) the product of run no. 1 of table 1 and (c) the ceramic specimen (without any fibre reinforcing material).

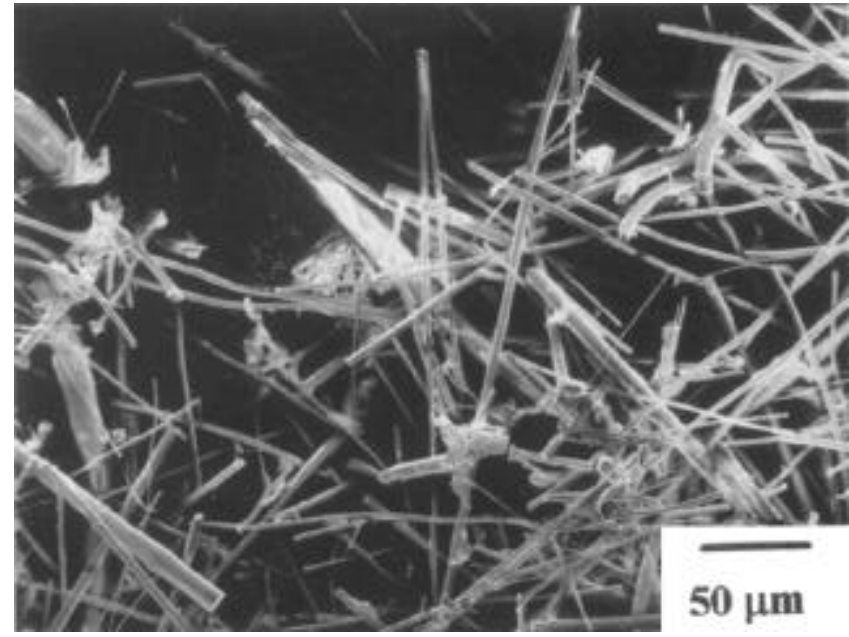

Figure 2. SEM of the as-received (uninfiltrated) mullite fibre preform.

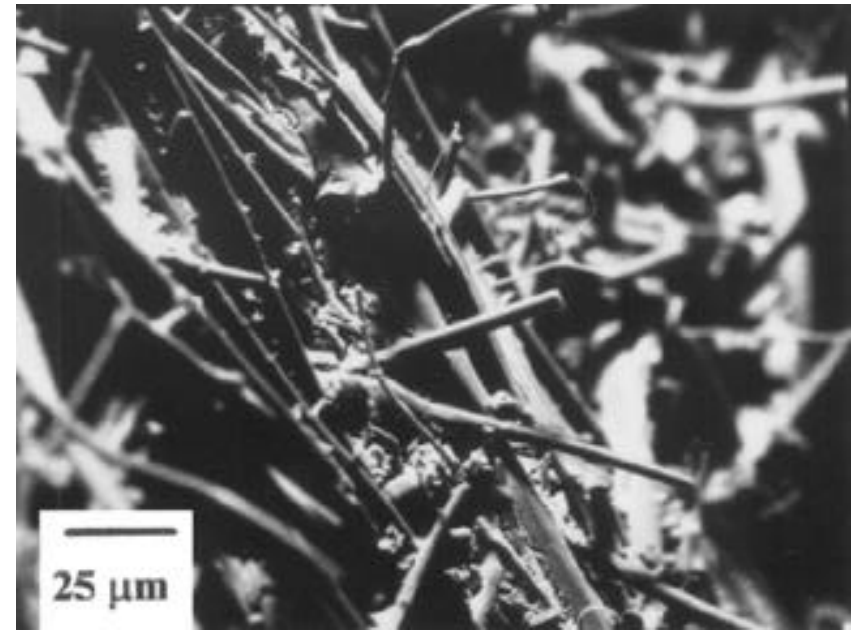

Figure 3. SEM of the fracture surface of the product of run no. 1 of table 1 showing fibre pull-out. 


\section{Conclusions}

A sol-gel vacuum infiltration technique has been developed for the fabrication of near-net-shape CMCs with pseudo-elastic character using discontinuous mullite fibre preform with 15 vol.\% of fibre content and $\mathrm{ZrO}_{2} \cdot 10$ wt.\% $\mathrm{Y}_{2} \mathrm{O}_{3}$ sol as the infiltrant.

\section{Acknowledgements}

The authors thank Dr K K Phani, Composite Division, CGCRI, Kolkata, for providing valuable suggestions throughout this work and colleagues of the X-ray and
SEM Sections for material characterization. Partial financial assistance from the Aeronautics Research and Development Board (AR\&DB), Ministry of Defence, Govt. of India, is also thankfully acknowledged.

\section{References}

Chakrabarty P K, Chatterjee M, Naskar M K, Siladitya B and Ganguli D 2001 J. Eur. Ceram. Soc. 2135

Gu X, Trusty P A, Butler E G and Ponton C B 2000 J. Eur. Ceram. Soc. 20675

Russell-Floyd R S, Cooke R G, Laurie J and Hammett F W 1993 J. Am. Ceram. Soc. 762635 